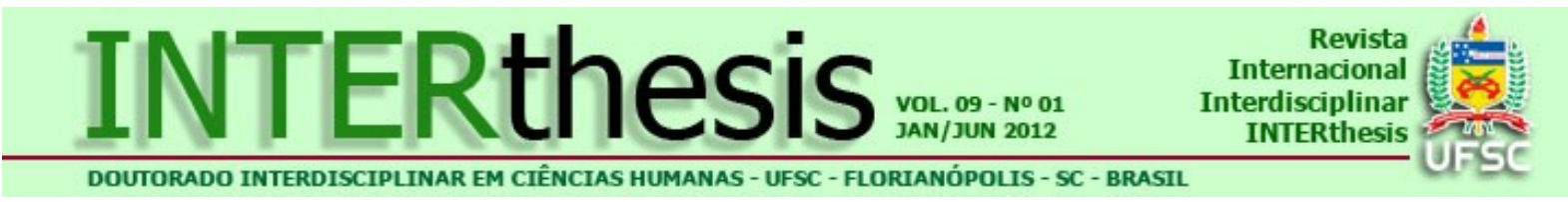

\title{
A INTERDISCIPLINARIDADE NO ESTUDO DA LITERATURA AFRICANA DE LÍNGUA PORTUGUESA
}

\section{THE INTERDISCIPLINARITY IN THE STUDY OF AFRICAN LITERATURE IN PORTUGUESE LANGUAGE}

\section{LA INTERDISCIPLINARIEDAD EN EL ESTUDIO DE LA LITERATURA AFRICANA EN IDIOMA PORTUGUÉS}

\author{
Izabel Cristina dos Santos Teixeira ${ }^{1}$
}

\section{RESUMO:}

Este trabalho traz um relato de experiência do ensino de literatura africana de língua portuguesa, na Universidade Federal do Tocantins, realizado em conjunto com um projeto de extensão interdisciplinar, desenvolvido em três etapas, em conjunto com professores de escolas de ensino fundamental e médio do Tocantins.

Palavras-chave: Literatura africana. Ensino de literatura. Interdisciplinaridade. Debate acadêmico. Redes de reflexão.

\section{ABSTRACT:}

This work brings a report on the teaching experience of African literature in Portuguese language, at the Federal University of Tocantins, held in conjunction with an interdisciplinary extension project, developed in three stages, together with elementary and high school teachers of Tocantins.

Keywords: African Literature. Teaching of literature. Interdisciplinary. Academic debate. Network of reflection.

\section{RESUMEN:}

Este trabajo aporta un informe de experiencia en la enseñanza de la literatura africana en idioma portugués, en la Universidad Federal de Tocantins, que se realizó/realizado en conjunto con un proyecto de extensión interdisciplinario, desarrollado en tres etapas, con los maestros de escuelas primarias y secundarias de Tocantins.

Palabras clave: Literatura Africana. Enseñanza de la literatura. Interdisciplinariedad. Debate académico. Redes de reflexión.

\footnotetext{
${ }^{1}$ Professora da Universidade Federal do Tocantins, Campus de Araguaína. Atua com literaturas africanas de língua portuguesa, onde investiga feminismo e meio ambiente (Ecofeminismo), desenvolvendo abordagens interdisciplinares. Pesquisadora do Núcleo de Estudos das Diferenças de Gênero (NEDiG). E-mail: izabelcristina@uft.edu.br
}

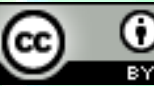
Esta obra foi licenciada com uma Licença Creative Commons - Atribuição 3.0 Não Adaptada. 


\section{INTRODUÇÃO}

Este trabalho tem por objetivo socializar uma experiência didática, que vem sendo realizada no Curso de Graduação em Letras- UFT (Campus Universitário de Araguaína), há três anos (2009-2011).

A disciplina "Introdução às literaturas africanas de língua portuguesa" começou a ser ministrada na Universidade Federal do Tocantins (UFT), para o curso de graduação em Letras, a partir de 2005, por exigência da Lei 10.639/03.

Algum tempo depois (2009), foi idealizado um projeto de extensão, integrado o às atividades de ensino dessa literatura, que resultou na ampliação de redes de reflexões em torno da história e cultura da África, em todos os níveis de ensino formal (fundamental, médio e superior), concentrado na cidade de Araguaína e em seu entorno.

Mais do que atender à demanda da lei acima referida, vimos, a partir daí, a possibilidade de se criarem outros espaços de debates, encontros, congressos, no Tocantins, visando a abordagens interdisciplinares sobre valores da cultura africana na prática pedagógica de professores de diferentes níveis de ensino, por meio da formulação de um trabalho conjunto e integrado entre universidade-escola pública.

Até então, a literatura africana oscilava entre ser ignorada ou marginalizada, na maioria das instituições de ensino locais, já que, ao que parece, aí, cabia, apenas, aos professores de História a função de dar visibilidade à cultura do "Continente Negro" no Brasil.

Após análise de alguns resultados obtidos nos seminários propostos e apresentados em sala de aula, desde a época em iniciamos o trabalho com a literatura africana (2005), e nos cinco anos seguintes, na recém-criada Universidade Federal do Tocantins (2003), houve, aos poucos, por parte de alunos, uma manifestação em torno da possibilidade de se levar às escolas de ensino, fundamental e médio, o conteúdo apresentado nas aulas que desenvolvemos juntos. É que muitos acadêmicos atuavam na prática docente, e estavam cientes de um certo "vazio" sobre a representação da África, presente nas obras literárias, que adotávamos na elaboração de seminários temáticos, nos locais em que eles atuavam, como professores. Assim, a partir da colocação do problema, propusemos à UFT um projeto de palestras, com temas dispostos na literatura, a fim de integrar os três níveis de ensino (superior, médio e fundamental). Para tanto, convidamos 
professores efetivos das escolas a participarem de sua elaboração, e formamos uma equipe multidisciplinar para desenvolvê-lo.

Denominado "África-Brasil-África", o projeto foi divido em etapas, a serem realizadas, anualmente, a partir de 2009 , em datas significativas: treze de maio (libertação dos escravos) e /ou vinte de novembro (dia da consciência negra).

Em resumo, a proposta do projeto era a seguinte: ano a ano, se realizaria um fórum por meio do qual se proporia o tema e o desenrolar da atividade, no ano seguinte, fora do âmbito da universidade, ou seja, um seminário de exposição pública, extra-muros da academia.

Entre as duas datas, se realizaria um ciclo de palestras - "Algumas Áfricas em Nós...", denominação propositadamente ambígua, mas que servia aos nossos propósitos de, aos poucos, criar dúvidas e despertar novos interesses pela cultura africana, disseminada nas narrativas debatidas nos seminários, ainda na sala de aula, no curso de Letras/UFT.

Em princípio, as duas primeiras atividades teriam lugar na Universidade (Fórum e Seminário), e a última (Ciclo de palestras), nas escolas de ensino fundamental e médio, proporcionando uma troca bastante significativa, em termos de conteúdo, além de promover a integração de todos os níveis de ensino formal, numa proposta de trabalho interdisciplinar, possível, a partir da literatura africana, por ela conjugar várias abordagens, como por exemplo: história, geografia (cultural e física), relações de gênero e filosofia do pensamento africano.

O projeto, como um todo, assim, como já frisamos, teve início na sala de aula, nas leituras, debates, seminários entre grupos de acadêmicos, sobre aspectos gerais da cultura africana e sua história, na ficção produzida pelos cinco países de língua oficial portuguesa e daí, seguiu para a primeira experiência "extra-muros" da academia, ou seja, o ciclo de palestras.

$\mathrm{Na}$ sala de aula, escolhemos livros de Angola, Moçambique, Cabo Verde, Guiné-Bissau e São Tomé e Príncipe, todos amplamente analisados e discutidos à luz da teoria pós-colonial que nos serviu de suporte. 


\section{AS LITERATURAS AFRICANAS DE LÍNGUA PORTUGUESA E A TEORIA PÓS- COLONIAL}

Conforme afirma o crítico Geral Moser (1993, p.45) "A literatura em língua portuguesa foi a primeira a aparecer em África e a última a ser revelada ao mundo". Entre pesquisadores, há um consenso em torno dessa afirmação, da mesma forma sobre o fato de que as peculiaridades históricas das cinco colônias também terem contribuído para a singularidade de suas literaturas, segundo palavras de Hamilton (1999, p.16), por isso, nas três últimas décadas da época colonial, a literatura de reivindicação cultural, protesto social e combatividade vinham preparando a cena para a emergência da escrita atual (pós-colonial) nos cinco países africanos de língua portuguesa. Dessa forma, textos de poemas, contos, romances e peças teatrais das literaturas africanas de língua portuguesa foram, no geral, direcionados a fazer oposição ao regime colonial, para, após a libertação, produzir uma literatura que, na maior parte, tinha cunho político, e celebrava a vitória sobre o regime imperialista.

Mais adiante, passada essa fase de euforia contra o sistema colonialista, os escritores passaram a produzir uma literatura que transitava entre dois espaços: o da escritas em português e a vivência de seu mundo africano, de acordo com Maria Nazareth Soares Fonseca e Teresinha Taborda Moreira (2011).

O resultado do trânsito entre os dois mundos (colonial e pós-colonial), ao que parece, é que, em particular, cada uma das literaturas desempenha um papel para o povo colonizado, em que se destaca, não apenas as qualidades estéticas, mas sua importância histórico-literária, constituindo, em cada ex-colônia, um marco na especificidade em direção a uma literatura nacional. Tais peculiaridades também são exemplos, a nosso ver, possíveis para uma referência à pluralidade das "Áfricas", cujos "nós", nos diversos níveis de entendimentos, temos procurado esclarecer na execução das atividades do projeto de extensão África-Brasil-África desenvolvidos até agora.

Após esse breve relato sobre as literaturas africanas de língua portuguesa, não podemos deixar de mencionar que sua produção se difundiu mais intensamente no mundo, após a Independência que cada colônia experimentou. Ou seja, elas se inserem no período denominado "pós-colonial". 
Bil Ashcroft, Gareth Griffins e Helen Tiffin (1992, p.2) usam esse termo, de forma muito apropriada, para incluir todas as culturas que estiveram sujeitas ao processo colonial, desde o seu início até o presente, as quais têm em comum, o fato de emergirem, justamente, da experiência da colonização, e nelas representam tensões entre sociedade colonizada e poder imperial, ao mesmo tempo em que evidenciam suas características distintivas, corroborando com Robert Fraser (2000) quando este declara que as literaturas pós-coloniais são aquelas que surgem em países que passaram e foram além da sentença ou jugo da colonização. Neste sentido, o autor identifica e destaca alguns estágios no desenvolvimento das literaturas pós-coloniais, sobretudo nas narrativas. São elas:

1) Pré-coloniais, bastante diversas na natureza e, por isso, podem ser orais ou escritas;

2) coloniais ou imperiais, escritas durante a vigência da colonização. Estas mantêm certa cumplicidade com seus interesses;

3) de resistência, escritas durante o período das lutas por independência, com fins ideológicos;

4) de construção do ideal de nação, evidenciado no período pósindependência, marcada por um sentimento de esperança e euforia generalizada;

5) de conflitos internos, influenciada pela desilusão que se seguiu à Independência, ressaltando a herança política da colonização e a crítica do desempenho das elites nativas governantes;

6) transculturais, que evidenciam a idéia de que a nação, como um ponto de referência para a sensibilidade, torna-se esparsa, sendo substituída por conceitos de coletividade, de identidade, mais fluida e mais complexa.

Em uma das etapas do ciclo de palestras, esses aspectos foram levantados, na literatura, quando da apresentação de seus temas de destaque, bem como sua inserção teórica no pós-colonial.

O entendimento da teoria pós-colonial, além de propor abordagens interdisciplinares, as quais estão contempladas nos Parâmetros Curriculares Nacionais (PCNs), faz com que a África, metaforicamente falando, traga à tona, outros temas (transversais), como, por exemplo, as abordagens sobre relações de 
gênero. Segundo Thomas Bonnici (2000, p16) o estudo do pós-colonial "proporciona a leitura de uma relação de analogia entre metrópole/colônia, ou colonizador/colonizado, e seus distintos processos de assimilação intercultural. Nessa relação, muitas vezes, por exemplo, no tocante ao gênero, se sobressai o feminino. Segundo o autor, "a mulher da colônia é uma metáfora da mulher como colônia". Assim sendo, ele afirma que, se o homem foi colonizado, nas sociedades pós-coloniais, a mulher foi duplamente colonizada. Suas constatações incidem sobre romances escritos por Jean Rhys, Doris Lessing, Toni Morrison e Margaret Atwood, concluindo que, entre tantos, um dos objetivos da teoria pós-colonial é investigar sua relação com o feminismo (relações de gênero), para, enfim, desenvolver políticas públicas de "integração da mulher marginalizada à sociedade". Assim, em relação às nossas abordagens das literaturas africanas, nas palestras apresentadas nas escolas, identificamos a possibilidade de mostrar as relações de gênero de forma comparativa, a partir dos exemplos presentes nas obras lidas, as quais mencionaremos à frente.

Nas apresentações públicas (fórum, seminário e ciclo de palestras), antes de iniciarmos as abordagens na literatura, tínhamos o cuidado de localizar cada um dos países no mapa da África, destacando características de sua geografia físicas (localização, fronteiras, acidentes geográficos e rede hidrográfica), indicadores econômicos e educacionais, e aspectos culturais peculiares (música, costumes, crenças religiosas).

Em seguida, apresentamos a literatura, e tivemos a oportunidade de desmistificar muitas abordagens estereotipadas dos países, por meio do estudo apurado das narrativas, até então, desconhecidas nas escolas. Os livros, inicialmente debatidos em sala de aula, na universidade, foram: de Angola, Mayombe (Pepetela, 2004); de Moçambique, Vinte e Zinco (Couto, 1999); da GuinéBissau, No fundo do canto (Semedo, 2007); de São Tomé e Príncipe, "Cores e sombras de São Tome e Príncipe (Silva, 2001) e de Cabo Verde, Os flagelados do vento leste (Lopes, 2001). Além desses autores, incluímos dois outros que não eram africanos, como um português, radicado em Angola António Lobo Antunes, autor de Os cus de Judas (2003), além de Joseph Conrad (polonês, naturalizado inglês), em cuja obra - O coração das trevas (2006) - mostra, aparentemente, a perspectiva de leitura de uma África exótica, impotente para os desafios da Modernidade gestada no Ocidente, no século XIX. 
Para intercalar tais leituras com as reflexões pós-colonialistas, analisamos obras críticas de Fratnz Fanon (1961), Albert Memmi (1978), Edward Said (1993), Hommi Bhabha (2005) e Kwame Anthony Appiah (1997), que muito acrescentaram às "possíveis traduções" de leitura dados às comparações entre obras lidas e viés teórico explicativo.

\section{AS NARRATIVAS AFRICANAS - NAS AULAS E PALESTRAS - À LUZ DA TEORIA PÓS-COLONIAL: ALGUMAS CONSIDERAÇÕES}

Antes de sairmos para as escolas para realizar as palestras sobre os romances lidos, fizemos vários debates em sala de aula, visando a esclarecer as leituras, dando-lhes suportes teóricos e, também, para adequar as obras aos níveis de ensino dos alunos (fundamental e médio) que nos ouviriam, por, mais ou menos, uma hora, a cada quinze dias, em pátios e auditórios reservados pelas escolas para o evento proposto.

O primeiro romance lido foi O coração das trevas (Conrad, op.cit.). Esta narrativa (século XIX) é um relato de memória, em que o personagem Marlow, um marinheiro, conta, aos passageiros de um navio de Cruzeiro, no rio Tâmisa (Inglaterra), sua ida`a África, em um barco a vapor, atravessando o rio Congo. $\mathrm{O}$ citado marinheiro, servindo a uma companhia exploradora inglesa, é destacado para trazer de volta Kurtz, trabalhador de uma firma inglesa, cuja trajetória pessoal simboliza a mesma trajetória do homem branco europeu (dito civilizado) em contato com o continente africano "primitivo". À medida que viaja no continente, Marlow vai retratando a crueldade do mundo dos brancos, em meio à "escuridão" da África. A narrativa foi objeto de muitas questões, associadas a uma perspectiva de leitura dicotômica - de bem/mal, primitivo/moderno, em que o mundo africano é entendido como o locus dos mais baixos valores civilizatórios, a necessitar da assistência material da Europa, a fim de sair de seu estado de "trevas" .

O outro romance, Mayombe (Pepetela), cujo tema é a guerra pela libertação colonial angolana, serve de contraponto ao primeiro. Como espécie de documento social, mesmo sendo ficção, ele explica, pela voz de vários narradores-personagens, a consciência que cada um tem da luta pela libertação do país (Angola). De um modo geral, um a um, os personagens desenvolvem uma reflexão particular sobre sua motivação em estar em um "fogo-cruzado", lutando pela independência, à 
medida que as origens de cada um deles vão se evidenciando de forma distinta, que os une na recusa ao processo de colonização, no ato de expulsão de suas próprias terras e, enfim, na organização dos combates.

Ainda em Angola, partimos para a leitura de Os Cus de Judas (Antunes, op.cit., autor português, médico psiquiatra). A narrativa enfoca a trajetória de um soldado português que servia ao exército colonialista. Tendo sido educado dentro dos padrões da burguesia portuguesa, diante do contato com a situação na África, vê entrar em decadência seus valores, suas crenças e, ainda, sua própria vida. O texto, comparativamente falando, é o outro lado da guerra de Mayombe (Pepetela, op.cit.), já que essa guerra foi desastrosa para ambos os lados - do colonizador e do colonizado, pois nenhum, na prática, escapa da "loucura" que representa a própria necessidade da guerra.

Da mesma forma, o a novela Vinte e Zinco (Couto, op.cit.) mostra como o "Vinte e Cinco de abril de 1974", data tão significativa para Portugal, pela queda da ditadura salazarista aí instalada por quase quarenta anos, se refletiu em Moçambique, e faz emergir cenas do colonialismo, arraigadas no imaginário, tanto dos colonizados, quanto dos colonizadores. Na então colônia, essa data não significou o fim da colonização, o que só veio a ocorrer no ano seguinte, em junho de 1975. Com esta narrativa, então, entramos em contato com Moçambique, e discutimos a situação colonial, profundamente marcada pelo preconceito, tanto étnico e quanto cultural.

Em seguida, migramos para outras paragens, e adotamos as leitura da coletânea de poesia No fundo do canto (Semedo, op.cit.), vinda da Guiné-Bissau. Nela, a experiência da guerra também foi ressaltada, pois os poemas, traçam um eixo sobre a história recente do pais, e dos horrores desse evento. O seu fim marca, também, a tentativa de afirmação de uma identidade nacional, conforme nos asseguram a maioria dos teóricos pós-coloniais. Para isso, os poemas de Semedo mergulham no interior do país, evidenciando tradições, aspectos da cultura da Guiné-Bussau, dentre os quais o culto aos antepassados, recorrente nos exemplos das tradições africana, de um modo geral.

Bem próximo da Guiné-Bissau, fomos ao encontro da literatura das ilhas de Cabo Verde, com o romance Os flagelados do vento leste (Lopes, op.cit.). Nele, o tema de destaque é a seca no país, em meio ao conflito chuva/estiagem que deixa o camponês completamente enfraquecido. Transpondo figuras e situações do 
cotidiano, a narrativa vai mostrando os contrastes de sonho/realidade, permeando a luta pela sobrevivência no arquipélago.

Por fim, escolhemos Cores e Sombras de São Tomé e Príncipe (Silva, op.cit.), de um outro conjunto de ilhas, o de São Tomé e Príncipe. O enredo traz a história de Mariana, a narradora, uma mulher que ama a Ilha de São Tomé, em que viveu ao lado do marido, Américo Santos (português branco), ali radicado como comerciante, e seu processo de adaptação a uma sociedade crioula.

As escolhas dos romances e da poesia recaíram na hipótese de consistência da possível leitura da "realidade" oferecida por autores que nos possibilitaram o entendimento, mais direto e criticamente, dos aspectos gerais do "Continente Negro", adotando a interdisciplinaridade como método de leitura. Neste sentido, os autores até aqui citados, e tantos outros, se debruçam sobre um das questões mais freqüentes - a "diferença"- refletida na possibilidade de se pensar a identidade quer nacional, social e/ou cultural da África, como um processo de reconfiguração constante. Tal questão perpassa as leituras, sobretudo auxiliadas pelos estudos teóricos que não a ignoram na abordagem da colonização de cada país africano e, especialmente, os que nos interessam de forma mais imediata, pela constituição de sua literatura em língua portuguesa.

Além disso, procuramos conhecer também aspectos da crítica pós-colonial, a respeito desse foco, observando as reflexões de autores como José Luis Cabaço (2004, p.2), moçambicano, para quem “a África era e é naturalmente marcada pela diferença em relação à referência universal do mundo em que somos periferia: o da cultura euro-americana". Neste sentido, vimos a possibilidade de intercalar seu pensamento ao método de leitura contapontística, proposto por Edward Said (2003), entre as literaturas africanas e as ocidentais, por isso as escolhas dos romances incluíram, de início, Joseph Conrad e António Lobo Antunes. Dessa forma, tivemos um apanhado geral de características e valores agregados, nos pensamentos que evidenciaram os contrastes culturais. Atentamos para o cuidado com o "olhar" dirigido para essa "diferença" africana, e estudamos as obras literatura com essa perspectiva: cada uma, por sua própria dicção, delinearia a afirmação de seus valores. Dentre eles, podemos citar a ancestralidade como exemplo de uma de suas matrizes de maior significado, conforme já sinalizamos antes.

A respeito dos contrastes "entre-mundos", Regina Chaves (2004, p.147) afirma que "a brusca ruptura no desenvolvimento cultural do continente africano - o 
contato com o mundo ocidental, estabelecido sob a atmosfera de choque e a intervenção direta na organização de seus povos - constituíram elementos de peso na reorganização das sociedades que fizeram a independência de cada um de seus países, não apenas os de língua portuguesa". Assim, segundo Chaves (idem), tais fatos, que ocorreram no complexo quadro da conjuntura internacional dos anos de 1970, bem como as independências, nada disso daria conta do "desejo de acertar o passo na direção do projeto utópico que mobilizara os africanos". Com efeito, como herança, o colonialismo, um dos temas mais debatidos na literatura africana póscolonial, deixava grandes lacunas na História das ex-colônias e Chaves (idem) observa que a escrita de muitos autores, de diferentes lugares e sob diferentes perspectivas, assumem o papel de preencher, com o seu saber, esse vazio que a consciência vinha desvelando.

Um tanto seguros pelas incursões teóricas, durante as apresentações das palestras, os acadêmicos, em suas abordagens, puderam ressaltar, nos textos ficcionais, a relação da literatura com a chamada História recente desses países, sobretudo de Angola e de Moçambique, muitas vezes, utilizando-se dos mapas da África para confirmarem toponímias mencionadas nos romances representativos desses países. Assim, vimos que Mayombe (Pepetela, op.cit.) e Vinte e Zinco (Couto, op.cit.), serviram, por suas descrições, como uma variedade de significados, e visões que, postas ao sabor da teoria e da crítica pós-colonial, foram dinamizando as leituras, ao longo das exposições nas escolas de Tocantins.

De fato, a África possui uma literatura muito variada, dispersa entre oralidade e escrita. E, embora incontestavelmente, as raízes étnicas do Brasil sejam, em larga escala, africanas, o desconhecimento em relação ao continente faz com que proliferem visões estereotipadas e preconceituosas sobre ele, como o que se apresenta em $O$ coração das trevas (Conrad, op.cit.). Nesse caso, nossa grande motivação, ao elaborar o projeto África-Brasil-África, era desmistificar leituras como a desta última obra, uma vez que ela serve de exemplo, pois o autor oferece inúmeros detalhes da colonização inglesa na costa africana, e seu ideal salvacionista, de livrar a África de sua "selvageria". Com isso a mission civiliatrice, romanceada pelo autor, de acordo com Said (1995, p.63), "está ligada a projetos não só cruéis mas..." (ironicamente falando - grifo nosso) “...levar luz aos lugares e povos escuros deste mundo"(...). 
Said (idem) considera esta obra uma espécie de limitação trágica de Conrad, por ele, embora podendo enxergar com clareza o alcance do imperialismo europeu sobre a África, o qual consistia essencialmente em pura dominação e ocupação de territórios, ele (Conrad) não conseguia raciocinar que esse mesmo imperialismo teria acabar, para que, enfim, os "nativos" (africanos) pudessem viver livres da dominação européia.

O coração das trevas (Conrad, op.cit.), então, nas nossas abordagens, levava em conta a visão de um autor "inglês" que, ao que parece, afinava-se com uma posição eurocêntrica, levando-nos a analisá-la a "contrapelo", comparando-a com as outras dos autores africanos, revelando algumas "Áfricas", representadas na ficção, o que gerou debates muito oportunos.

\section{REPRESENTAÇÒES DE ÁFRICA NOS LIVROS DIDÁTICOS}

No encerramento das palestras, informamos aos presentes que, no ano seguinte (2010), teríamos um fórum cuja mesa de abertura seria "A África nos livros didáticos". Para isso, conduzimos um levantamento de publicações de material didático no Tocantins, a fim de estreitar, mais ainda, essa atividade interativa entre a Universidade e as escolas de ensino fundamental e médio no Estado. Daí, em consenso, destacamos os livros Mãe África, Pai Brasil (Araújo, 2008) e História cultural afro-brasileira e africana (Simões Pires; Mechi; Melo; e Oliveira, 2008). Ambos, adotados no ensino médio de Tocantins, fazem recortes de âmbito antropológico, geográfico, histórico e sociológico sobre África e Brasil, enfatizando a presença da África na realidade social e cultural brasileira.

Nos livros citados, destaca-se que, pelo tráfico de escravos, essa presença proporcionou, por muito longo tempo, o transporte de manifestações da África para o Brasil e, ainda que tivessem sido reprimidas, permaneceram vivas, atuantes "e com inegável presença no cotidiano nacional, conforme também admitem Serrano e Waldman (2008, p13) e Del Priore e Venâncio (2004, p.2)

$\mathrm{Na}$ pesquisa do livro didático, tínhamos a preocupação em analisar, paralelamente ao projeto África-Brasil-África, como estava, até então, a formação do docente, já que, a partir das atividades de extensão universitária, haveria uma nova alternativa para os professores dirimirem suas dificuldades decorrentes de um formação inicial sem o conhecimento sobre a África contextualizado, atualizado e 
com menos distanciamento entre teoria e prática, apontando para uma formação crítica e reflexiva, nos termos propostos por Antonio Nóvoa (1995, p.25), para quem o professor deve atuar como um orientador de uma prática pedagógica inovadora, que enfatiza a qualidade de ensino envolvendo diversas abordagens (interdisciplinaridade), que compõem o currículo, levando, com isso, a um aperfeiçoamento da prática didático-pedagógica.

Assim, vimos, então, que o a experiência do Projeto África-Brasil-África tem sido um modelo possível para, no contexto do ensino, "o docente construir sua profissão", de forma permanente no espaço de discussão e de ação, com parcerias entre os três níveis de ensino apontando para uma direção sobre o que fazer e como fazer, de forma compartilhada, uma vez que, de acordo com Nóvoa (idem, p 25), “ a formação não se constrói por acumulação (de cursos, conhecimentos, ou técnicas), mas, sim, por meio de uma flexibilidade crítica sobre as práticas", e esse, sem dúvida, foi um dos nossos alcances significativos do projeto mencionado.

Mais ainda, pensamos em como avaliar esse trabalho, diante de seus três anos de atividade, e solicitamos, por meio de um pequeno questionário, em aberto, como cada participante analisou seu desenvolvimento. Após o levantamento das respostas, constatamos que, como projeto África-Brasil-África tem continuidade, outras propostas puderam ser sugeridas e, assim, outros temas serão abordados, proporcionando um trabalho criativo intercambiável, com adequações e complementações, sempre que for o caso, do material didático usado em sala de aula, nas escolas locais.

Analisando o peso de cada atividade, e o compromisso de realizá-las, ano a ano - Fórum, Seminário e Ciclo de Palestras (nas escolas) - podemos dizer que a literatura africana de língua portuguesa foi o meio utilizado para a formação de professores interessados em desenvolver uma nova sensibilidade para as questões da África, adotando o campo interdisciplinar, já que esta literatura está enraizada em um meio sócio-cultural e geográfico que proporciona amplas reflexões sobre o modus vivendi dos africanos, tão afinados com o de muitos brasileiros, de um modo geral. Por isso, sabemos que, antes de tudo,

quando se conhece melhor a África, pode-se conhecer melhor o próprio Brasil, pois de lá veio grande parte de nossos antepassados. E porque, também, muitos episódios da história brasileira estiveram relacionados ao que ocorria no lado de lá do Atlântico. Não se trata de saber mais somente 
para deleite intelectual: compreender a história e cultura africanas pode ser a diferença entre acolher e conviver versus recusar e discriminar. (Silva, 2007, p.64)

R. Inter. Interdisc. INTERthesis, Florianópolis, v.9, n.1, p. 334-348, Jan./Jul. 2012 


\section{REFERÊNCIAS}

ANTUNES, António Lobo. Os cus de Judas. Rio de Janeiro: Objetiva, 2003.

APPIAH, Kwame Anthony. Na casa de meu pai: a África na filosofia da cultura. Rio de Janeiro: Contraponto, 1997.

ARAÚJO, Edivaldo Sampaio. Mãe África, Pai Brasil. Recife: Soler, 2008.

ASCROFT, Bill; NGRIFFITHS, Gareth; TIFFIN, Helen. The empire writhes back. Theory and practice in post-colonial literatures. London; New York: Routledge, 1994.

BHABHA, Hommi. O local da cultura. Belo Horizonte: EdUFMG, 2005.

BONNICI, Thomas. O pós-colonial e a literatura: estratégias de leitura. Maringá: UEM, 2000.

CABAÇO, José Luis. A questão da diferença na literatura moçambicana. Revista Via Atlântica, São Paulo, n.7, p.61-69, 2004.

CHAVES, Regina. O passado e o presente na Literatura africana. Revista Via atlântica, São Paulo, n.7, p.147-161, 2004.

CONRAD, Joseph. O coração das trevas. São Paulo: Martim Claret, 2006.

COUTO, Mia.Vinte e Zinco. Lisboa: Caminho, 1999.

DEL PRIORE, Mary; VENÂNCIO, Renato. (orgs.). Ancestrais: uma introdução à história da África Atlântica. 9. ed. Rio de Janeiro: Elsevier, 2004.

FANON, Frantz. Os condenados da terra. Rio de Janeiro: Civilização Brasileira, 1973.

FONSECA, Maria Nazareth Soares Fonseca; MOREIRA, Terezinha Taborda. Panorama das literaturas africanas de língua portuguesa. Disponível em: $<$ www.ich.pucminas.br/posletras/Nazareth_panorama.pdf $>$. Acesso em: 30 ago. 2011. 
FRASER, Robert. Lifting the sentence. A poetics of postcolonial fiction. Manchester; New York: Manchester University Press, 2000.

HAMILTON, Russel G. A literatura dos PALOP e a teoria pós-colonial. Revista Via Atlântica, São Paulo, n.3, p.16-29, 1999.

LOPES, Manuel. Os flagelados do vento leste. 2. ed. Lisboa: Veja, 2001.

MEMMI, Albert. $O$ retrato do colonizado precedido pelo retrato do colonizador. Rio de Janeiro: Paz \& Terra, 1978.

MOSER, Gerald; FERREIRA, Manuel. Bibliografia das literaturas africanas de expressão portuguesa. Lisboa: Lello \& editores, 1999.

NÓVOA, António. Os professores e sua formação. 2. ed. Portugal: Dom Quixote, 1995.

PEPETELA. Mayombe. Luanda. [s.I.]: Edições Maianga, 2004.

SAID, Edward. Cultura e imperialismo. Rio de janeiro: Companhia das Letras, 1995.

SAID, Edward. Orientalismo. Rio de Janeiro; Companhia das letras, 1993.

SEMEDO, Odete. No fundo do canto. Belo Horizonte: Nandyala, 2007.

SERRANO, Carlos; WALDMAN. Memórias D`África: a temática africana em sala de aula. 2. ed. São Paulo: Cortez, 2008.

SILVA, Alberto da Costa e. Como os africanos civilizaram o Brasil. Revista Entre Livros, São Paulo, n.6, p. 64-69, 2007.

SILVA, Otilina. Cores e sombras de São Tomé e Príncipe. Lisboa: Colibri, 2001.

SIMÕES PIRES, Antônio Liberac et al. História e cultura afro-brasileira e africana. Fortaleza: Editora Printcolor, 2008.

Artigo:

Recebido em: 07/09/2011

Aceito em: $24 / 04 / 2012$

R. Inter. Interdisc. INTERthesis, Florianópolis, v.9, n.1, p. 334-348, Jan./Jul. 2012 